\title{
Transtornos Globais do Desenvolvimento e Escolarização: conhecimento em perspectiva
}

\author{
Carla K. Vasques' \\ Claudio Roberto Baptista' \\ 'Universidade Federal do Rio Grande do Sul (UFRGS), Porto Alegre/RS - Brasil
}

\begin{abstract}
RESUMO - Transtornos Globais do Desenvolvimento e Escolarização: o conhecimento em perspectiva. O presente artigo aborda a escolarização de sujeitos com Transtornos Globais do Desenvolvimento (TGD) a partir de 107 teses e dissertações produzidas no período entre 2000-2012, das diretrizes inclusivas e da hermenêutica-filosófica. Considerando os temas abordados, as questões recorrentes, as lacunas e as epistemologias, são analisadas as concepções de TGD, de escola e escolarização. Como resultados: o incremento dos estudos; a proliferação dos sentidos sobre estes alunos e as possibilidades escolares; a atualização de antigos impasses perante o novo, o diferente. Se, no âmbito dos princípios, são reconhecidas a igualdade e as diferenças, no âmbito das pesquisas ainda persiste a noção do diferente como desigual.

Palavras-chave: Educação Especial. Escolarização. Transtornos Globais do Desenvolvimento. Estado do Conhecimento.
\end{abstract}

ABSTRACT - Pervasive Developmental Disorders and Schooling: knowledge in perspective. This article examines the education of subjects with Pervasive Developmental Disorders (PDD) considering 107 theses and dissertations produced between 2000 and 2012, as well as the guidelines for inclusion and the philosophical hermeneutics. The concepts of PDD, school and education are analyzed here considering the subjects under study, the recurring questions, the gaps and the epistemologies. Results obtained include: increased enrollments; the multiplying of meanings regarding these students and the educational possibilities; an update of old dilemmas before the new and the different. If at the level of principles equality and differences are both recognized the notion of different as unequal still remains within the research context.

Keywords: Special Education. Education. Pervasive Developmental Disorders. State of the Knowledge.

Educação \& Realidade, Porto Alegre, v. 39, n. 3, p. 665-685, jul./set. 2014

Disponível em: <http://www.ufrgs.br/edu_realidade> 
Transtornos Globais do Desenvolvimento e Escolarização

$$
\begin{array}{r}
\text { O ímpio afirma que o contrassenso é normal na Biblioteca, e } \\
\text { que o razoável (ou mesmo a humilde e pura coerência) é uma } \\
\text { miraculosa exceção. } \\
\text { Jorge Luis Borges. A Biblioteca de Babel }
\end{array}
$$

A inclusão, compreendida a partir do movimento que defende a universalização dos direitos humanos, desponta como perspectiva norteadora das políticas públicas, das propostas de atendimento e de formação profissional em diferentes áreas do conhecimento e setores sociais ${ }^{1}$. Nas últimas décadas, a educação especial tem contemplado os influxos dessa discussão no que se refere ao acesso de alunos com deficiências no ensino comum e, sobretudo, ao pertencimento a estes espaços a partir do reconhecimento da alteridade. Tais preposições suscitaram um grande número de debates e produções voltados, dentre outros, para o atendimento educacional especializado, a implementação das políticas, a formação de professores, o currículo e a gestão. Apesar desses movimentos, é ainda amplo o desconhecimento sobre a educação escolar frente às demandas inclusivas (Baptista; Caiado; Jesus, 2008).

A fim de construir um horizonte compreensivo que tenha como pressuposto a valorização dos processos de escolarização, percorreremos os caminhos da produção científico-acadêmica brasileira, teses e dissertações. Diferentes autores justificam a importância de inventariar e sistematizar determinadas áreas e temáticas no sentido de compreender os movimentos, a amplitude, as tendências teóricas e metodológicas. Além de contribuir para o avanço do conhecimento, tal esforço, afirmam, é capaz de incidir no âmbito das práticas docentes e dos processos de democratização e qualificação da escola e da educação (Ferreira, 2002; Sander, 2007). Compartilhamos estas apostas tendo por foco as pesquisas produzidas no período de 2000-2012, o campo dos Transtornos Globais do Desenvolvimento (TGD) e as lentes da hermenêutica filosófica.

Hans-Georg Gadamer (1900-2002), filósofo alemão, discute, em Verdade e Método, obra de 1960, o acontecer da compreensão. O compreender por meio da interpretação. O diálogo entre a tradição e o intérprete; os aspectos linguísticos da compreensão versus a impossibilidade de uma interpretação objetiva.

A compreensão é uma pré-condição para a existência do homem. A consciência de que ele próprio e o mundo existem. O objetivo não é validar uma interpretação e compor uma verdade unitária. Trata-se, antes, de renunciar à busca de um fundamento último do qual emanam certezas absolutas; questionar modelos cristalizados que objetivam e naturalizam a condição humana; defender a historicidade dos conceitos, que precisam de constantes interpretações.

Nesse processo, Gadamer (2007) afirma a centralidade da linguagem nas produções humanas. Escrevemos aquilo que compreendemos. E não compreendemos aquilo que a linguagem não consegue descrever, construir, inscrever. Morada do ser, o sujeito e o mundo são seres da 
linguagem. Existe, contudo, um resto que a palavra, a letra, não recobre. Um impossível, um vazio de essência e determinação a partir do qual se constrói um saber sempre contingencial. Ao esvaziar a condição humana de uma substancialidade prévia, seu pensamento permite pensar o estar no mundo como uma posição enunciativa construída na relação com a cultura, com o simbólico, com o outro.

Como se compreende? Trata-se de um ato carregado de preconceitos e pressuposições. Daí a importância de um movimento contínuo de autoesclarecimento acerca dos nossos juízos e pressupostos. O processo reflexivo sobre as bases do proceder é fundamental, pois o não esclarecimento leva à desresponsabilização (Hermann, 2002).

Em uma pesquisa do tipo bibliográfico, tais pressupostos transcendem a convencionalidade da leitura, do fichamento ou da utilização mecânica das informações. A potência não reside no mapeamento de informações, apesar de esta constituir-se como uma etapa fundamental do processo, mas nas inúmeras possibilidades advindas do ato de interpretar. Da interação entre o texto e o leitor, despontam múltiplas tonalidades compreensivas. Arte de ler o invisível, de olhar mais além e de reparar. Artes que se fazem por meio de uma outra arte, a do diálogo. Diálogo a ser estabelecido no sentido de abertura ao outro, apostando na produtividade de se expor e assumir uma postura reflexiva. Não se trata, porém, de um esforço tradutor ou conciliador, mas do de oferecer visibilidade às diferenças e, quem sabe, criar redes de inteligibilidade entre elas.

Com os fios da teoria, das normativas legais que dão borda à experiência da vida e das pesquisas inventariadas, tramamos as perguntas que orientam nossa reflexão sob a inspiração do ensaio (Adorno, 2003), oferecendo consistência aos argumentos pela tessitura dos fios, e não pela busca de uma definição.

\section{Do Inventário Enciclopédico à Construção do Acervo: gestos de leitura}

$$
\begin{array}{r}
\text { Todos lemos a nós e ao mundo à nossa volta para vislumbrar o } \\
\text { que somos e onde estamos. Lemos para compreender, ou para } \\
\text { começar a compreender. Não podemos deixar de ler. Ler, quase } \\
\text { como respirar, é nossa função essencial. } \\
\text { Alberto Manguel, Uma história da leitura. }
\end{array}
$$

O ponto de partida desta investigação foi à valorização das perguntas: quais os conhecimentos produzidos, entre os anos de 2000 e 2012, nos programas de pós-graduação brasileiros sobre sujeitos com Transtornos Globais do Desenvolvimento? ${ }^{2}$ Quais as áreas envolvidas? Qual o lugar conferido à escolarização?

As bases de dados utilizadas para o levantamento das fontes documentais foram o Portal Capes (Teses e Dissertações) e a BDTD (Biblioteca Digital de Teses e Dissertações). 
Como categorias de busca, palavras-chave, utilizamos nomenclaturas referendadas pelos diferentes campos teóricos que abordam esse tema: autismo; autismo infantil; psicose infantil; distúrbios globais do desenvolvimento; transtornos invasivos do desenvolvimento; transtornos globais do desenvolvimento; asperger; espectro autístico; condutas típicas. Em um segundo momento, cruzamos tais termos com os seguintes buscadores: educação; escolarização; atendimento educacional especializado; inclusão escolar.

Identificamos 366 produções acadêmicas distribuídas entre os anos de 2000 e 2012. As referências foram acessadas integralmente, constituindo o acervo ou corpus documental da pesquisa. Quanto aos procedimentos analíticos, lemos, inicialmente, todos os resumos. Posteriormente, organizamos um banco de dados com as seguintes categorias: áreas do conhecimento; instituições de ensino superior e regiões geográficas; periodicidade dos estudos; níveis de mestrado e doutorado; objetos de investigação e metodologias ${ }^{3}$. Deste primeiro gesto de leitura, obtivemos um panorama da produção discente. Posteriormente, os trabalhos que faziam menção, direta ou indiretamente, à escolarização foram lidos integralmente.

O campo dos Transtornos Globais do Desenvolvimento, do autismo e das psicoses infantis têm uma história recente e complexa. Desconhecidos, inicialmente, como entidade, faziam parte do grande grupo das idiotias, categoria nosográfica vigente até o século XIX que englobava um conjunto de problemas deficitários.

O processo de transformação desses conceitos ocorreu a partir do século XX e pode ser subdividido em dois grandes momentos. O primeiro deles corresponde aos primeiros 40 anos, quando o movimento inicial - e essencial - foi o de aceitação da existência de psicopatologias na infância. O segundo momento caracteriza-se pela revolução na história das psicopatologias, o que ocorreu a partir de 1943, com as publicações de Leo Kanner. Mais importante do que a descrição de um novo quadro nosológico - o Distúrbio Autístico do Contato Afetivo -, seu ato definiu uma psicopatologia própria da infância e da criança (Berquez, 1991).

O quadro descrito por Kanner foi amplamente difundido entre os profissionais. Tornou-se, contudo, evidente que nem todas as crianças apresentavam características similares às identificadas inicialmente. Criaram-se, desse modo, inúmeras investigações sobre os problemas do desenvolvimento e, sobretudo, intensificaram-se as controvérsias ligadas à terminologia e à etiologia.

Analisando-se as fontes documentais, observamos a continuidade dos embates teóricos e conceituais. As opiniões e as perspectivas são díspares e polêmicas, não havendo consenso em relação a quem são esses sujeitos, quais as suas possibilidades subjetivas, sociais, educacionais e quais as estratégias ou recursos que podem favorecer (ou não) o seu desenvolvimento, constituição, escolarização etc. 
Tamanha complexidade convocou 248 pesquisadores das Ciências Humanas (67,8\%), 80 das Ciências da Saúde (21,9\%), 24 da Linguística, Letras e Artes (6,5\%), 10 das Ciências Biológicas (2,8\%), dois das Engenharias (0,5\%), um das Ciências da Computação $(0,25 \%)$ e um das Ciências Exatas (0,25\%). Considerando as áreas, na psicologia encontramos a maior concentração de pesquisas $(175=71 \%)$, seguida pela educação com 73 documentos (29\%).

Identificamos cinco grandes eixos temáticos: escolarização (107 = $29,3 \%)$, terapêuticas e terapias $(101=27,6 \%)$; avaliação, escalas e testagens $(90=24,6 \%)$; diagnóstico/etiologia ( $51=13,9 \%)$; inclusão social (17 $=4,6 \%$ ).

De forma geral, o acervo manifesta o frágil e recente interesse dos poderes públicos na construção de dispositivos legais que permitam maior agilidade e qualidade assistencial, escolar e clínica; os processos relacionados à avaliação (escalas e testagens), às terapêuticas e terapias e, sobretudo, à escolarização como temáticas privilegiadas pelos autores e teorias; o diálogo ainda incipiente entre as disciplinas. Há também alguns consensos: certa unidade em relação à multiplicidade de expressões clínicas e subjetivas, a precariedade dos serviços oferecidos e a provisoriedade dos conhecimentos até então construídos.

Em meio a tantas verdades, o acervo pode ser considerado como lugar de contiguidade e ruptura. Continuidade com o discurso científico moderno, com o prestígio do pensamento matemático como medida de todas as ciências e da própria filosofia; com a crença da razão como forma única de conhecer a verdade, suspeitando-se de todo o conhecimento, intuitivo, estético etc.; com a liberdade incondicional do homem para reger seu destino; com ideias e ideais de sujeito e autonomia; com a convicção de que se pode ignorar a tradição, dedicando-se inteiramente ao futuro (Chauí, 2005; Hermann, 2002).

Manguel (2006) afirma que, frente a essa leitura clara, diurna, sistemática e estruturada, podemos construir outra forma de ler: noturna, adúltera, com limites e certezas borrados. Nesse sentido, o acervo pode ser lido também como questionamento desse ideal científico e da racionalidade técnica que lhe é característico; do método como única forma válida de construção do conhecimento; das amarras epistemológicas e grades de registros. Buscam-se, assim, rupturas capazes de abalar, perturbar, a familiaridade do nosso pensamento, das nossas formas de ler, perceber e interpretar.

Um segundo gesto de leitura deteve-se na geografia acadêmico-científica dos 107 documentos relativos ao eixo escolarização. Como o tema é abordado? Quais as questões recorrentes, as lacunas e as tendências?

É no jogo entre o familiar e o estranho, o legível e o ilegível, que a perspectiva gadameriana situa as possibilidades de compreender. Entre tradição, texto e intérpretes, uma delicada trama institui e modi-

Educação \& Realidade, Porto Alegre, v. 39, n. 3, p. 665-685, jul./set. 2014

Disponível em: <http://www.ufrgs.br/edu_realidade> 
fica sentidos, ressignifica diretrizes, alternativas, impasses e disputas interpretativas. Não há um único sentido, tampouco se pode tudo saber, conhecer, interpretar. Este limite permite contrapor a objetivação, a domesticação e a tiranização do outro, do diferente, por vezes engendradas em leituras ingênuas ou politicamente corretas.

Com tal impulso ético, propomos a conversação entre produção discente e as políticas de educação especial. É importante sublinhar que grande parte das pesquisas sobre escolarização não se referem aos documentos legais e normativos diretamente, há alusões, notas de rodapé e silêncios ruidosos, principalmente quando se foca o fazer docente. É como se a prática pedagógica, o ensinar e o aprender fossem autodeterminados. Tomamos outra via interpretativa ao compreendermos que a letra da lei direciona, produz e inscreve contornos importantes no estado do conhecimento. Não se trata, porém, de continuidade, interdependência direta ou de subserviência. As políticas colocam problemas para os sujeitos e as instituições. A teoria e o esforço intelectual permitem uma discursividade diferente ao desvelarem, subverterem e interrogarem naturalizações e objetivações, construindo certa alteridade em relação aos interesses políticos e a imediatismo da prática. O texto político estabelece contornos de uma realidade cuja qualidade se joga na arena das disputas, resistências e embates. A letra da lei não circunscreve completamente as possibilidades do acontecimento. Como letra, implica leitura. E como leitura implica - por mais que queira varrer o equívoco de seu enunciado - abertura aos sentidos. A leitura nunca é linear, unívoca ou consensual.

\title{
A Escolarização entre Rupturas, Repetições e Esquecimentos: rastros de uma leitura
}

\author{
Porque buscamos definições de identidade nas palavras e qual é, \\ nessa busca, o papel de contador de histórias? Como a linguagem \\ determina, delimita e amplia nossa imaginação [e construção] \\ do mundo? Como as histórias que contamos nos ajudam a perce- \\ ber a nós mesmos e aos outros? E, para concluir, as histórias se- \\ rão capazes de mudar quem somos e o mundo em que vivemos?
}

Alberto Manguel, A cidade das palavras

À margem da agenda política do Estado, a educação especial tradicionalmente se organizou como atendimento educacional especializado, em classes e escolas especiais, substitutivo ao ensino comum. Espaços e propostas diferenciados para aqueles que, por suas qualidades sociais, culturais, genéticas, comportamentais etc., diferiam da normalidade. Para as lentes do Estado, dos professores, dos especialistas e pesquisadores, ser diferente era ser anormal, justificando a desigualdade de escolarização, de acesso e permanência na escola.

A persistência, o crescimento e aprofundamento deste quadro, em conjunto com a universalização da educação básica e as conferên- 
cias internacionais que versam sobre os que estão do lado de fora, introduziram no cenário político as diretrizes inclusivas. Nesse sentido, o Brasil implementou uma série de leis, políticas e programas voltados para a redução da desigualdade e inclusão escolar.

Nos últimos 19 anos, a educação especial acompanha tal movimento ao ressignificar-se como área de conhecimento e modalidade de atendimento educacional. A Resolução n. 02/2001 CNE-CEB, por exemplo, avança ao prever escolarização necessariamente no ensino comum. Nessa mesma década, percebemos uma série de iniciativas com vistas à ampliação dos sujeitos a serem escolarizados (Baptista, 2011).

Com a Política Nacional de Educação Especial na Perspectiva da Educação Inclusiva de 2008, esse enfoque se adensa:

Para além de um documento orientador, a Política passa a se constituir um marco na organização do sistema educacional inclusivo [...] fortalecendo o conceito de educação especial que não concebe, nem em caráter extraordinário, a utilização desse atendimento em substituição à escolarização realizada no ensino regular (Griboski, 2008, p. 57).

Neste texto e nos documentos legais que o sucederam, os sujeitos com TGD têm pela primeira vez garantida a sua escolarização, sendo identificados como aqueles que apresentam:

[...] quadro de alterações no desenvolvimento neuropsicomotor, comprometimento nas relações sociais, na comunicação, estereotipias motoras. Incluem-se nessa definição alunos com autismo clássico, síndrome de Asperger, síndrome de Rett, transtorno desintegrativo da infância (psicoses) e transtornos invasivos sem outra especificação (Brasil, p. 9, 2008).

É um nascimento simbólico para essas crianças e adolescentes no campo da legislação educacional, acompanhado pela possibilidade de questionarmos diagnósticos realizados segundo categorizações fechadas.

As definições do público alvo devem ser contextualizadas e não se esgotam na mera categorização e especificações atribuídas a um quadro de deficiência, transtornos, distúrbios e aptidões. Considera-se que as pessoas se modificam continuamente transformando o contexto no qual se inserem (Brasil, 2008).

As deficiências e os TGD são descritos não só com alterações orgânicas estruturais ou funcionais, mas como decorrentes também das relações humanas, econômicas, sociais etc. Na constituição do sujeito como deficiente, deficitário, ou não, sublinha-se a força dos encontros, da cultura, das políticas como possibilitadoras ou limitadoras do humano.

Educação \& Realidade, Porto Alegre, v. 39, n. 3, p. 665-685, jul./set. 2014 
O ordenamento legal transforma a escola e o incremento das matrículas é percebido nas bases censitárias e nas pesquisas. O direito à educação garante acesso à escolarização. Os direitos à igualdade e à diferença reorganizam os serviços, os conceitos e os profissionais envolvidos com o contexto escolar, tencionando novos contornos também no âmbito das pesquisas ${ }^{4}$. Reescrevem-se as agendas sociais, políticas e científico-acadêmicas.

É nesta processualidade histórica, cultural e política que compreendemos o paulatino aumento no número de pesquisas atentas aos processos de escolarização, bem como os temas e suas abordagens.

\section{Gráfico 1 - Distribuição dos Documentos Considerando o} Ano de Publicação e Nível das Pesquisas

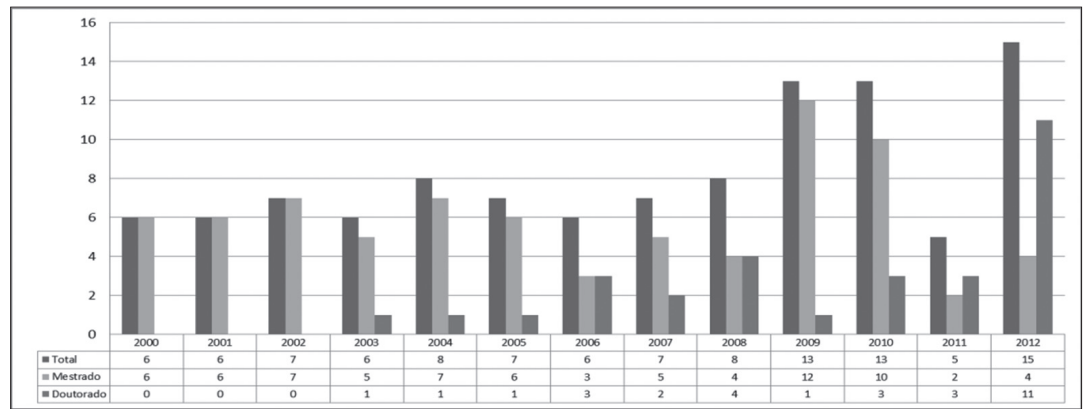

Fonte: Brasil. MEC/CAPES/BDTD e Bibliotecas Digitais IES. Dados sistematizados pelos autores.

De acordo com o Gráfico 1, percebemos o aumento de $150 \%$ no número total de pesquisas, entre os anos de 2000-2012. Destas, 77 (71,9\%) são de mestrado e $30(28,1 \%)$ de doutorado.

Temos 32 Instituições de Ensino Superior (IES), com concentração nas Regiões Sudeste e Sul, e predominância da Universidade Federal do Rio Grande do Sul (18); Universidade Federal de São Carlos (17); Universidade do Estado do Rio de Janeiro (11); Universidade de São Paulo (8) e Universidade Católica de Brasília (7).

Tabela 1 - Número de Documentos por Origem Regional de sua Produção

\begin{tabular}{|l|c|l|c|}
\hline IES & $\begin{array}{c}\mathbf{N} \text {. } \\
\text { Total }\end{array}$ & IES & $\begin{array}{c}\text { N. } \\
\text { Total }\end{array}$ \\
\hline $\begin{array}{l}\text { UNIVERSIDADE FEDERAL DO RIO } \\
\text { GRANDE DO SUL }\end{array}$ & $\mathbf{1 8}$ & $\begin{array}{l}\text { PONTIFÍCIA UNIVERSIDADE } \\
\text { CATOLICA DE GOIÂS }\end{array}$ & $\mathbf{1}$ \\
\hline $\begin{array}{l}\text { UNIVERSIDADE FEDERAL DE SÃO } \\
\text { CARLOS }\end{array}$ & $\mathbf{1 7}$ & $\begin{array}{l}\text { PONTIFÍCIA UNIVERSIDADE } \\
\text { CATÓLICA DO RIO GRANDE DO SUL }\end{array}$ & $\mathbf{1}$ \\
\hline $\begin{array}{l}\text { UNIVERSIDADE DO ESTADO DO RIO } \\
\text { DE JANEIRO }\end{array}$ & $\mathbf{1 1}$ & UNIVERSIDADE BRAZCUBAS & $\mathbf{1}$ \\
\hline UNIVERSIDADE DE SÃO PAULO & $\mathbf{8}$ & $\begin{array}{l}\text { UNIVERSIDADE CATÓLICA DE } \\
\text { PERNAMBUCO }\end{array}$ & $\mathbf{1}$ \\
\hline $\begin{array}{l}\text { UNIVERSIDADE CATÓLICA DE } \\
\text { BRASILIA }\end{array}$ & $\mathbf{7}$ & $\begin{array}{l}\text { UNIVERSIDADE DO ESTADO DE } \\
\text { SANTACATARINA }\end{array}$ & $\mathbf{1}$ \\
\hline $\begin{array}{l}\text { UNIVERSIDADE ESTADUAL PAULISTA } \\
\text { JULIO DE MESQUITA FILHO }\end{array}$ & $\mathbf{5}$ & UNIVERSIDADE DO VALE DO ITAJAÍ & $\mathbf{1}$ \\
\hline $\begin{array}{l}\text { UNIVERSIDADE FEDERAL DO } \\
\text { ESPIRITO SANTO }\end{array}$ & $\mathbf{5}$ & UNIVERSIDADE FEDERAL DA BAHIA & $\mathbf{1}$ \\
\hline
\end{tabular}




\begin{tabular}{|l|c|l|c|}
\hline $\begin{array}{l}\text { UNIVERSIDADE FEDERAL DE SANTA } \\
\text { MARIA }\end{array}$ & $\mathbf{3}$ & $\begin{array}{l}\text { UNIVERSIDADE FEDERAL DE JUIZ DE } \\
\text { FORA }\end{array}$ & $\mathbf{1}$ \\
\hline $\begin{array}{l}\text { UNIVERSIDADE METODISTA DE } \\
\text { PIRACICABA }\end{array}$ & $\mathbf{3}$ & $\begin{array}{l}\text { UNIVERSIDADE FEDERAL DE } \\
\text { PERNAMBUCO }\end{array}$ & $\mathbf{1}$ \\
\hline $\begin{array}{l}\text { PONTIFÍCIA UNIVERSIDADE } \\
\text { CATOLICA DE CAMPINAS }\end{array}$ & $\mathbf{2}$ & $\begin{array}{l}\text { UNIVERSIDADE FEDERAL DE } \\
\text { UBERLÂNDIA }\end{array}$ & $\mathbf{1}$ \\
\hline $\begin{array}{l}\text { PONTIFÍCIA UNIVERSIDADE } \\
\text { CATOLICADE SÃO PAULO }\end{array}$ & $\mathbf{2}$ & UNIVERSIDADE FEDERAL DO CEARÁ & $\mathbf{1}$ \\
\hline $\begin{array}{l}\text { PONTIFÍCIA UNIVERSIDADE } \\
\text { CATOLICA DO RIO DE JANEIRO }\end{array}$ & $\mathbf{2}$ & UNIVERSIDADE FEDERAL DO PARANÁ & $\mathbf{1}$ \\
\hline UNIVERSIDADE DE PASSO FUNDO & $\mathbf{2}$ & $\begin{array}{l}\text { UNIVERSIDADE FEDERAL DO RIO DE } \\
\text { JANEIRO }\end{array}$ & $\mathbf{1}$ \\
\hline $\begin{array}{l}\text { UNIVERSIDADE FEDERAL DE SANTA } \\
\text { CATARINA }\end{array}$ & $\mathbf{2}$ & $\begin{array}{l}\text { UNIVERSIDADE FEDERAL DO RIO } \\
\text { GRANDE DO NORTE }\end{array}$ & $\mathbf{1}$ \\
\hline $\begin{array}{l}\text { UNIVERSIDADE PRESBITERIANA } \\
\text { MACKENZIE }\end{array}$ & $\mathbf{2}$ & UNIVERSIDADE SÃO MARCOS & $\mathbf{1}$ \\
\hline $\begin{array}{l}\text { UNIVERSIDADE REGIONAL DE } \\
\text { BLUMENAU }\end{array}$ & $\mathbf{2}$ & UNIVERSIDADE TUIUTI DO PARANÁ & $\mathbf{1}$ \\
\hline
\end{tabular}

Fonte: Brasil. MEC/CAPES/BDTD e Bibliotecas Digitais IES.

Dados sistematizados pelos autores.

Escolarização, como categoria ordenadora e classificatória, refere-se aos direitos à educação, à igualdade e à diferença; à implementação das políticas de educação especial na perspectiva inclusiva no âmbito dos sistemas de ensino, das salas de aula e nas formas organizativas do trabalho pedagógico; ao ensino comum como espaço prioritário para ser aluno; à aposta na educabilidade. Tais questionamentos, tensionamentos e intencionalidades, conforme a Tabela 2 perpassaram diversos campos do conhecimento.

Tabela 2 - Distribuição conforme as Áreas do Conhecimento

\begin{tabular}{|c|c|c|}
\hline GRANDES ÁREAS & SUBÁREAS & ÁREAS \\
\hline \multirow{8}{*}{$\begin{array}{l}\text { CIÊNCIAS } \\
\text { HUMANAS (100) }\end{array}$} & \multirow{4}{*}{ Educação (73) } & Educação especial (62) \\
\hline & & Fundamentos da educação (6) \\
\hline & & Tecnologia educacional (4) \\
\hline & & Planejamento educacional (1) \\
\hline & \multirow{4}{*}{ Psicologia (27) } & Psicologia do desenvolvimento humano (13) \\
\hline & & Psicologia do ensino e da aprendizagem (4) \\
\hline & & Tratamento e prevenção psicológica (7) \\
\hline & & Psicologia social (2) \\
\hline \multirow{3}{*}{$\begin{array}{l}\text { CIÊNCIAS DA } \\
\text { SAÛDE (3) }\end{array}$} & Saúde Coletiva (1) & Saúde pública (1) \\
\hline & Fonoaudiologia (1) & Distúrbios da comunicação (1) \\
\hline & Educação Física (1) & Esportes adaptados (1) \\
\hline $\begin{array}{l}\text { CIÊNCIAS EXATAS } \\
\text { E DA TERRA (1) }\end{array}$ & Matemática (1) & Educação matemática (1) \\
\hline $\begin{array}{l}\text { CIÊNCIAS DA } \\
\text { COMPUTAÇÃO (1) }\end{array}$ & $\begin{array}{l}\text { Metodologia } \\
\text { e Técnicas da } \\
\text { Computação (1) }\end{array}$ & Computação aplicada (1) \\
\hline $\begin{array}{l}\text { LINGUÍSTICA, } \\
\text { LETRAS E ARTES (2) }\end{array}$ & Artes (2) & $\begin{array}{l}\text { Música (1) } \\
\text { Artes plásticas (1) }\end{array}$ \\
\hline
\end{tabular}

Fonte: Brasil. MEC/CAPES/BDTD eBibliotecas Digitais IES. Dados sistematizados pelos autores.

Resumir, condensar e estruturar: movimentos que, ao construírem visibilidades e luzes, produzem, paradoxalmente, seleções, esquecimentos e sombras. No esforço de descrever e compreender o estado do 
Transtornos Globais do Desenvolvimento e Escolarização

conhecimento sobre escolarização de sujeitos com TGD, cabe-nos, novamente, ressaltar: a presença de palavras, temas e subtemas comuns não implica compartilhar ideias e ideais. Não há uma única leitura sobre aluno, escola, educação, inclusão escolar etc. A existência de múltiplas interpretações impede consensos em relação aos alunos, suas possibilidades de aprendizagem e escolarização, bem como sobre a função da escola e da educação. Tais dissonâncias, se compreendidas a partir de uma processualidade histórico-cultural, não constituem um limite teórico-prático. Ao contrário, a pluralidade de sentidos pode representar um primeiro passo no sentido de admitir soluções diferentes para as questões suscitadas no encontro com estas crianças e adolescentes.

Classificação gera classificação, afirmam Borges (2007) e Perec (2006). Um novo gesto de leitura arrolou as pesquisas segundo seis amplos temas (Tabela 3), desdobrados em subtemas de acordo com as especificidades elencadas pelo autor ${ }^{5}$.

Tabela 3 - Categorização das Pesquisas segundo Tema Abordado

\begin{tabular}{|l|c|}
\hline CATEGORIAS & N. DE ESTUDOS \\
\hline PROCESSOS DE ENSINO E APRENDIZAGEM & 31 \\
\hline TRABALHO PEDAGÓGICO & 25 \\
\hline DIAGNÓSTICO E PROCESSOS DE IDENTIFICAÇÃO & 21 \\
\hline RELAÇÕES ENTRE A CLÍNICA E A ESCOLA & 14 \\
\hline INCLUSÃO ESCOLAR & 09 \\
\hline RELAÇÕES ENTRE ESCOLA E FAMÍLIA & 07 \\
\hline & 107 \\
\hline
\end{tabular}

Fonte: Brasil. MEC/CAPES/BDTDe Bibliotecas Digitais IES. Dados sistematizados pelos autores.

Como ensinar tais crianças e adolescentes e o que eles podem aprender? Da mensuração das habilidades e dos perfis considerados típicos do autismo derivam processos de ensino e aprendizagem. É preciso identificar, avaliar e descrever comportamentos a fim de definir planos de ensino e metas de aprendizagem. Quais programas de ensino e de treinamento estruturados? A Metodologia TEACCH - Treatment and Education of Autistic and Communication Handicapped Children, o CFN - Currículo Funcional Natural e o PEI - Programa de Ensino Individualizado são considerados os mais adequados para as especificidades dos sujeitos em questão ${ }^{6}$.

Em outra perspectiva, os processos de ensino e aprendizagem são construídos no encontro entre sujeitos e instituições. Importa refletir sobre como a aprendizagem é concebida pelo professor; enfatizar o corpo como possibilidade de intercomunicação (gestos, deslocamentos, olhares); compreender a dinâmica relacional desse alunado e suas demandas para o docente. Como incidem os preconceitos, as representações sociais e os estigmas nas formas de ensinar e aprender são perguntas que motivam pesquisas qualitativas, estudos de caso individuais ou grupais. 
Considerando as dificuldades relacionais e os problemas de fala e linguagem, é possível pensar os recursos computacionais e tecnológicos como mediadores do ensino e da aprendizagem? A acessibilidade ao currículo, à comunicação e à tecnologia facilita o desenvolvimento da interação social ao permitirem a inclusão escolar de crianças com autismo, afirmam alguns pesquisadores.

Diferentes estudos focam o trabalho pedagógico em um contexto inclusivo: quais didáticas, conteúdos e técnicas são mais adequados para a prática em sala de aula? Como organizar os tempos e os espaços escolares? Como adaptar currículos, planos de ensino e de aula? Como avaliar quem parece não aprender? Qual formação continuada, estratégias, metodologias e conhecimentos são necessários para o desenvolvimento de didáticas e técnicas atentas às necessidades educativas especiais dos autistas?

As pesquisas abordam diferentes e, por vezes, conflitantes perspectivas teóricas, como, por exemplo, a Teoria da Modificabilidade Cognitiva Estrutural, o materialismo histórico, a perspectiva sistêmica e psicanalítica a fim de sublinhar a importância de uma postura crítica reflexiva, da docência compartilhada e da inovação pedagógica como condição de possibilidade.

Quem são estas crianças? O que é o autismo? Como aprendem? Quais suas características, manifestações e tipologias? Como são identificados nas escolas e nas redes de ensino? Na categoria diagnóstico, avaliação e processos de identificação, encontramos estudos provenientes da educação, da psicologia, da fonoaudiologia e da saúde pública. Duas perspectivas distintas são apresentadas: uma primeira, identifica e mensura os aspectos instrumentais das crianças com autismo (ou espectro autista) a fim de desenvolver e validar escalas e protocolos capazes de subsidiar programas educacionais individualizados e tratamentos psicoeducativos. Outro grupo de pesquisadores interroga os sistemas classificatórios e seus influxos nos processos de escolarização; o modelo médico e o esvaziamento do lugar e do professor em decorrência de uma leitura que considera os sujeitos com TGD como deficitários e inaptos, que hipervaloriza o conhecimento dos especialistas em detrimento do saber construído na experiência escolar. Tais pesquisas interrogam estes temas nas redes de ensino, na escola, na sala de aula, nas publicações e documentos especializados e acadêmico-científicos. Em busca de alternativas, muitos apostam no modelo social de deficiência como referência capaz de construir novas interpretações. Afirmam que a discriminação, as desvantagens e as incapacidades associadas aos TGD decorrem de inúmeros fatores, dentre os quais as representações sociais que banalizam o direito à educação e naturalizam as desigualdades escolares ao denegarem as condições sociais, políticas e econômicas na construção das (im)possibilidades de ser e estar na escola.

Como se estabelecem as relações entre o educar e o tratar? Quais são as condições para que o ensinar e o aprender se constituam? Par-

Educação \& Realidade, Porto Alegre, v. 39, n. 3, p. 665-685, jul./set. 2014. 675

Disponível em: <http://www.ufrgs.br/edu_realidade> 
tindo da função constitutiva da escola e da educação, os pesquisadores focam as relações entre a clínica e a escola. A presença de impasses e descompassos na convivência entre a comunidade escolar e alunos com TGD e os sofrimentos decorrentes desse encontro são temas que atravessam a inclusão escolar. Não se valora tampouco se considera como semelhante qualquer um e, para ocorrer tal reconhecimento, é necessário um trabalho a fim de que a não semelhança, ou ainda, a alteridade não se torne uma ameaça. Como o diálogo entre o tratar e o educar, entre a clínica e a escola incide na constituição dessa possibilidade? Como sustentar estes percursos quando se percebe uma visão que valoriza a dimensão socializadora da escola em detrimento da sistematização dos conhecimentos formais?

Estudos abordam a leitura e a escrita como subjetivantes para tais crianças; a partir da clínica psicopedagógica, psicanalítica e da inclusão escolar no ensino público, pesquisas tratam as especificidades destas produções, devido ao transbordamento da subjetivação psicótica no texto, da estranheza que tais escritas e leituras causam no espaço escolar e das possibilidades de construção do conhecimento para estes sujeitos desde que tal estranhamento não seja naturalizado, domesticado. Os autores defendem a necessidade de construir espaços de reconhecimento e valoração da singularidade, a fim de que a escola ocupe uma função constitutiva e terapêutica.

Quais os limites e possibilidades derivadas do acesso e permanência no ensino comum? Como sustentar a inclusão escolar de alunos com TGD? Quais seus efeitos para a escola, a gestão e o trabalho docente? Como temas a serem pesquisados, destacam-se as significações, os impasses e as representações dos professores; os efeitos destas representações nas relações entre escola, família e alunos; o encaminhamento para a escola comum, o ingresso nesse espaço e as estratégias para a permanência e evolução no ensino fundamental e na educação infantil.

Apostando na educabilidade e, principalmente, na abordagem histórico-cultural como lente teórica e ética, pesquisas apresentam o delicado e laborioso caminho em direção à alfabetização, ao lugar de aluno como aprendente e à possibilidade de habitar a escola em seus múltiplos espaços e margens.

Em outra vertente investigativa, pesquisadores focam o despreparo dos sistemas de ensino, das famílias, dos professores e das próprias crianças frente às demandas associadas à inclusão escolar. Com base no relato de docentes e de pais, arrolam falhas, impasses e sofrimentos oriundos de uma escola que tem por métrica a normalidade e a produção homogênea de fazeres e saberes.

Qual o lugar da família nos processos de escolarização? Como estabelecer relações que permitam um trabalho cooperativo? A família pode escolher qual o espaço mais adequado para matricular seu filho com TGD? Procurando apreender as percepções, os pontos de vista de pais, irmãos e/ou cuidadores em relação aos tratamentos, vivências 
institucionais, relacionais etc., autores ocuparam-se das relações entre escola e família no contexto do atendimento educacional especializado, da escola especial e daquela comum.

O tema circunscreve ainda um universo de significações, representações, afetos e reações decorrentes do convívio com a criança ou o adolescente autista no âmbito doméstico e/ou escolar. Por meio de estudos de casos, qualitativos e quantitativos, descreve-se, mensura-se e interpreta-se a dinâmica familiar, os estilos comunicativos e, mais recentemente, as estratégias de coping, ou seja, os recursos utilizados pelos familiares para adaptarem-se a circunstâncias adversas, tais como os esforços despendidos para lidar com situações estressantes, crônicas ou agudas, advindas dos comportamentos inadequados, estereotipados, agressivos de seus filhos ou irmãos. Capacitar o profissional da saúde e da educação para atender tais demandas, por meio de atendimento clínico e programas educacionais, bem como para identificar as nuances e as alterações do funcionamento familiar para, então, propor intervenções são alguns objetivos destes pesquisadores.

Em nosso breve mapa do estado do conhecimento sobre a escolarização de sujeitos com TGD, chama atenção à presença incipiente de estudos que tematizam o atendimento educacional especializado como ação complementar; a recorrente pergunta pelos limites e impossibilidades da inclusão escolar no contexto, inclusive físico, das escolas e classes especiais; a formação de professores centradas prioritariamente nos aspectos técnicos e instrumentais de um saber-fazer profissional; a educação infantil como lócus prioritário das ações inclusivas.

Quais concepções de TGD, de escola e escolarização fundamentam os estudos? A fim de ampliar nossos horizontes compreensivos, fez-se necessário colocarmos em perspectiva as vertentes epistemológicas em relação aos temas e subtemas categorizados.

Segundo os aportes teóricos de Sanchez Gamboa (1996) e Turato (2005), 17 (15,8\%) documentos situam-se na perspectiva empírico-analítica ou quantitativa. Esses estudos justificam-se a partir de pressupostos positivistas, como, por exemplo, a compreensão da ciência como atividade neutra e objetivada; a racionalidade técnica e instrumental; o sujeito e objeto separados para garantir a imparcialidade científica etc. O objetivo principal é estabelecer relações de causalidade entre os fenômenos considerados típicos do autismo a fim de aprimorar o processo de ensino e aprendizagem, de avaliação e trabalho pedagógico. A avaliação e a descrição minuciosa dos comportamentos observáveis são, para tanto, fundamentais. Com elas constroem-se distinções e fronteiras no espectro ou continuum autístico. Por meio de pesquisas experimentais ou quase experimentais generalizam-se percursos, didáticas, planos de ensino e programas de treinamentos.

Os procedimentos de investigação são objetivos e visam atingir medidas ou reflexões acuradas do objeto, tidas como independentes do pesquisador. Acredita-se na possibilidade de mensurar e predizer as-

Educação \& Realidade, Porto Alegre, v. 39, n. 3, p. 665-685, jul./set. 2014 677

Disponível em: <http://www.ufrgs.br/edu_realidade> 
Transtornos Globais do Desenvolvimento e Escolarização

pectos relacionados aos sujeitos com TGD e sua realidade. Passíveis de quantificação e de análise estatística, esses aspectos são susceptíveis de organizações sistemáticas, como, por exemplo, repertórios comportamentais, perfil comunicativo, adaptativo, cognitivo etc. Estas descrições são centrais para o processo educacional, na medida em que organizam currículos e propostas de intervenção em contextos residenciais, escolas especiais e no ensino comum. Trata-se da educação em uma vertente comportamentalista, voltada para o ensino e a aprendizagem de habilidades consideradas funcionais e úteis, cujo objetivo são mudanças comportamentais e atitudinais.

Para $90(84,2 \%)$ pesquisadores, a perspectiva fenomenológico-hermenêutica ou qualitativa estabelece uma crítica contundente ao objetivismo científico, propondo a subjetividade como fundante dos atos humanos e da realidade social. A partir de uma compreensão interpretativa, foca-se a experiência humana, a complexidade e o entorno histórico, social e cultural que a constitui. O processo interpretativo implica um movimento constante, num diálogo entre os sujeitos, situações e objetos investigados, não havendo início e fim absolutos (Sanchez Gamboa, 1996).

Em consonância com tal pressuposto, o propósito principal destes estudos é compreender a dinâmica (psíquica, inconsciente, cultural, histórica, escolar etc.) dos sujeitos com autismo e psicose infantil, bem como dos familiares, educadores e instituições. As etiologias e as interpretações são múltiplas, de acordo com os sistemas classificatórios, as diferentes explicações psicanalíticas, sócio-históricas, cognitivistas ou sistêmicas. Em alguns textos, sublinha-se a singularidade destas condições, em oposição a uma leitura atrelada aos padrões de normalidade. A partir de estudos de caso com professores, alunos e/ou instituições, pesquisas bibliográficas e teóricas, reflete-se sobre a inclusão escolar, as políticas públicas educacionais, a função constitutiva da escola e do educador. Nesse sentido, busca-se compreender as possibilidades e os limites no atual contexto escolar brasileiro, oferecendo visibilidade aos encontros minúsculos, únicos, construídos nas fronteiras de uma ou várias disciplinas.

Inúmeras discussões e controvérsias. Construído na encruzilhada de diversas orientações epistemológicas e diferentes racionalidades, o eixo escolarização caracteriza-se pela profusão de línguas e dialetos. As interpretações e lentes divergem, convergem, multiplicam-se, sufocam-se.

Concebida a partir dos sistemas classificatórios como a CID-10 (OMS, 2000) e o DSM-IV-R (Apa, 2002), a noção do autismo como um só quadro composto por diferentes níveis de gravidade (dependentes, sobretudo, da linguagem e/ou inteligência) é aceita pela maioria dos pesquisadores, independentemente da vertente epistemológica. $\mathrm{O}$ diagnóstico e a psicopatologia descritivos não são, contudo, interpretados uniformemente. Alguns autores não problematizam tais referências,

678 Educação \& Realidade, Porto Alegre, v. 39, n. 3, p. 665-685, jul./set. 2014 Disponível em: <http://www.ufrgs.br/edu_realidade> 
tratando-as genericamente, ou seja, utilizam-nas como forma de 'identificar' o sujeito a ser pesquisado, sem contextualizar a historicidade dos conceitos, seus limites e implicações; outros se situam nesse referencial enquanto a etiologia não é mais bem definida, o que temporariamente impossibilita outro tipo de classificação; há também os que se afirmam categoricamente teóricos. No gesto que toma nas mãos o texto que constitui esses manuais, verificam-se rasuras, ruídos na leitura, algumas passagens sublinhadas, outras esquecidas.

Fala-se de psicose infantil, de autismo, ou de psicose e autismo como duas situações diferenciadas. Outros dizem que nada disso existe, que o correto é referendar autismo ou espectro autista, conforme a noção de continuum, ou seja, um mesmo quadro, com diferentes graus de gravidade. Temos aqueles que afirmam: falamos de erros metabólicos, de transtornos neuropsiquiátricos que, mesmo sem um marcador biológico identificado, implicam déficits cognitivos. Outros replicam: falamos da loucura e, mais ainda, da loucura na infância, possuidora de características diferenciadas do adulto. Aí se diz, por exemplo, das mães geladeiras, culpadas pelas fortalezas vazias em que se transformaram seus filhos. Ou das psicoses e do autismo infantil como posições subjetivas.

O diálogo com os sistemas diagnósticos e as lógicas classificatórias é intenso, porém nem sempre suficientemente esclarecido. O ponto crucial da ausência de reflexão sobre os determinantes históricos e das concepções de sujeito presentes na elaboração dos diagnósticos está no fato de que diferentes entendimentos imprimem percursos escolares também diversos, cifrando destinos distintos.

\begin{abstract}
O lugar de sujeito, do professor e de aluno, fica subtraído, economizado, por uma causalidade que se impõe antes mesmo de qualquer ato que cada um deles possa inscrever. Uma causalidade que não se constrói a partir dos efeitos das práticas e dos encontros, mas que chega antes - antes dos próprios sujeitos -, retira da cena a responsabilidade (Rickes, 2004, p. 12).
\end{abstract}

Inscritos nas margens e nas entrelinhas de um conjunto significativo das pesquisas, percebemos o autismo, a psicose infantil e/ou TGD como fenômenos estritamente individuais, vinculados às noções de desvio e anormalidade. $\mathrm{O}$ apego descritivo às síndromes e 'constelações de sintomas' permanece furtivo e não esclarecido. A realidade do autista lhe é natural; sendo explicada pela ciência e explicitada por meio do diagnóstico, das classificações e avaliações. O fracasso ou limites dos processos de escolarização, nesta perspectiva, decorrem do aluno autista - em função de seus genes, alterações comportamentais, desequilíbrios neurológicos, afetivos etc. O diferente feito desigual é responsável pela desigualdade escolar. Para Arroyo (2010), essa perspectiva tem raízes profundas na cultura escolar brasileira. 
Outro sentido recorrente supõe, mesmo com referência ao Estado e às políticas, a culpabilização do professor diante dos impasses escolares e inclusivos. Há uma incapacidade técnica do professor para atender sujeitos com tamanhas necessidades educativas especiais. Da lógica tecnicista derivam como soluções programas adaptados e individualizados, de cunho comportamental ou cognitivista, em escolas comuns e especiais.

Alguns poucos estudos procuram entender o encontro entre esses alunos, seus professores e escolas tramado entre os enunciados políticos e os ditames diagnósticos, econômicos e históricos, um espaço entre. Ao ampliarem os horizontes compreensivos, complexificam-se as perguntas e as possíveis respostas, entendidas como parciais e provisórias. Toda fronteira inclui e exclui ao mesmo tempo e, na situação educativa, permanecerão aspectos imprevisíveis e zonas de sombra. A escolarização de alunos com TGD exige um trabalho a ser desenvolvido no coletivo, bem como a construção de um estilo próprio de ensinar e a responsabilização por um processo a ser sustentado em diferentes instâncias.

Do inventário enciclopédico à invenção de uma leitura, compreendemos que experiência da escolarização envolve uma construção compartilhada. Termos como autismo, psicoses infantis, TGD, escola, escolarização, inclusão escolar etc. referem-se a conceitos, construções linguísticas, oriundos de diferentes racionalidades e epistemologias. Sistemas mais ou menos fechados que armam determinadas perspectivas. A interpretação ocorre a partir dos horizontes compreensivos. Trata-se da historicidade, das racionalidades, das condições de produção dos textos, dos sentidos hegemônicos que amalgamam determinadas perspectivas. Há sempre o risco de essencializar ou naturalizar nossas lentes e concepções, sobretudo se generalizamos ou desconsideramos os limites do conhecimento, se despolitizamos seu conteúdo. Daí a necessidade do autoesclarecimento constante, da reflexão sobre as bases do nosso proceder.

\section{Sujeitos com TGD em Direção à Escola e ao Aprender: um horizonte em construção}

O que importa não é somente escutar coisas uns dos outros, senão escutar uns aos outros. Unicamente isso é compreender.

Hans-Georg Gadamer, Verdade e Método

Compreender é uma aventura perigosa e impossível em sua plenitude. Perguntar sobre a escolarização de sujeitos com Transtornos Globais do Desenvolvimento considerando as possíveis relações, diálogos e percalços constitutivos da produção discente brasileira, no período de 2000-2012, surpreendeu-nos a cada página. Constatamos os contatos mais íntimos entre as disciplinas, os desconhecimentos recíprocos 
mais totais e até mesmo mais depreciativos, os silêncios mais ruidosos e constrangedores. Em busca das múltiplas relações que se entrecruzam no acervo, percebemos que os textos, perfilados, lado a lado, contavam uma história que nenhum deles poderia contar sozinho. Oferecer visibilidade e voz a tal polifonia, contribuindo para multiplicar e matizar o olhar para e com estes sujeitos e suas possibilidades escolares, foi o principal desafio do presente artigo.

Na construção destas possibilidades, parece-nos urgente questionar a concepção de aluno e ensino ideal; de segurança e controle sobre o processo de ensino e aprendizagem; de sujeito como essência a ser desvelada, mensurada, rotulada. A experiência escolar envolve uma construção compartilhada a partir dos pressupostos a respeito de escola, educação, sociedade etc. O texto político - suas linhas, margens e entrelinhas - oferece uma primeira mirada, estabelece as bordas de uma arena onde se dá o balé dos significantes que, ao se articularem, engendram sentidos singulares. Quais as possíveis significações?

Responder a essa pergunta não constituiu o objetivo desse ensaio, mas antes esteve em nossa mira situar a necessariedade de sua colocação em cena. Consoantes com a inspiração ensaística, não buscamos começar “[...] com Adão e Eva, mas com aquilo que se deseja falar; diz o que a respeito lhe ocorre e termina onde sente ter chegado ao fim, não onde nada mais resta a dizer [...]" (Adorno, 2003, p. 16-17).

Com as diretrizes educacionais de caráter decisivamente inclusivas, um novo capítulo na educação especial e na agenda acadêmico-científica se inscreve. $\mathrm{O}$ direito à educação garante acesso irrestrito à escolarização. Os direitos à igualdade e à diferença reorganizam os serviços, os conceitos, a geografia das pesquisas, seus relevos, fronteiras e lacunas. Em que medida tais movimentos desconstroem sentidos que relacionam diferença à desigualdade, à anormalidade e à ineducabilidade?

Para Arroyo (2010), pela polarização que estabelecem, dentro-fora, incluído-excluído, as diretrizes inclusivas enfraquecem os ideais de superação das desigualdades na medida em que deslocam o foco para questões de pertencimento ou não aos espaços universais. Nesse sentido, correm sempre o risco de, ao invés de desconstruírem, reforçarem sentidos que relacionam diferença à desigualdade, inferioridade e não pertencimento. Perigo iminente que, para ser transposto, exige um trabalho articulado no cotidiano dos pesquisadores e profissionais das escolas, porque da letra da lei à atualização na vida há um longo caminho a percorrer. A letra abre espaço à produção de um sentido, mas não garante o vetor em que ele se inscreverá.

Considerando nosso acervo, são múltiplos os temas e temáticas abordadas, as formas de interpretar a política, de produzir e reproduzir sentidos relacionados à diferença pelo viés da desigualdade e/ou da identidade. Se, no âmbito dos princípios, são reconhecidas a igualdade e as diferenças, na pesquisa ainda persiste a noção do diferente como 
desigual. Equaciona-se o diferente à anormalidade e acaba-se por reproduzir (e justificar) a desigualdade. Nesse contexto, o fascinante e eficaz conhecimento científico, oferecido pelos manuais classificatórios, justifica compreensões e trajetórias escolares empobrecidas e objetivadoras. A eficácia e fascinação derivam da forma: um modelo descritivo, classificatório, no qual tudo está organizado, contemplado. O fechamento harmônico entre o que há e o que não há, o que é e o que não é. A representação de algo considerado claro, concluso, conhecido. Quais os efeitos desta equação harmoniosa frente às desmesuras do humano? Um saber totalizante que limita o universo do dito: os transtornos passam a ser fenômenos a priori, independentes do laço social que lhes dá existência. A escolarização de alunos com TGD é pautada pela impossibilidade, pela culpabilização dos sujeitos, sejam as crianças e/ou os professores.

Dessa posição enunciativa resulta um sentido com profundas raízes na cultura escolar: as práticas pedagógicas existem independentemente do contexto, das interpretações e das políticas. As diferenças orgânicas, sociais, psíquicas, comportamentais são equacionadas como identidades. Destas identidades derivam currículos e intervenções que justificam, inclusive, as desigualdades escolares. O autista! Deste estado, em que se é todos e não se é ninguém, a singularidade é subsumida pela repetição do idêntico. Gadamer afirma que a noção de identidade é nefasta para a justiça social. Em nome de uma diferença lida como identidade, retira-se de cena a alteridade, a diferença como condição de ser. Trata-se do não reconhecimento do outro, do seu apagamento.

O diferente como diferente. Em meio às nuances do compreender, no encontro com o outro, o plural, talvez seja possível reajustar focos, construir novos outros, ampliando e, talvez, modificando os horizontes compreensivos. A experiência hermenêutica advoga a disponibilidade para abertura, para o imprevisível. Aposta no diálogo; contudo, seu acontecimento requer ouvir o outro como um outro, mantendo sua alteridade. Esse é o desafio. Um desafio a ser sustentando por políticas de pertencimento, e não pelo "[...] ideal de unicidade como sinônimo de igualdade de direitos. Educação (em abstrato), direito (em abstrato) de todo cidadão (abstrato). Sem rostos" (Arroyo, 2010, p. 1386).

$\mathrm{Na}$ tentativa de articular igualdade e diferença, parece fundamental compreender o papel específico do sistema escolar e do campo acadêmico-científico na produção dos sujeitos diferentes em inferiores, anormais, ineducáveis ou (in)suportáveis. Considerando os alunos com TGD, tradicionalmente apartados dos processos escolares, muitas vezes reproduzimos essas formas históricas de pensá-los. As tentativas de reconhecer o diferente têm-se efetivado por meio da violenta abstração e, para afirmar o direito universal à educação, temos excluído o estranho, o outro, o diferente.

Há uma única compreensão deste movimento? Estabelecer um significado inflexível é acreditar que as políticas e as pesquisas podem 
existir independentemente do contexto e dos professores, alunos, escolas e pesquisadores; dos tempos e condições de leitura. O mundo valora os objetos/sujeitos da maneira como se relaciona com eles. Assim como esse valorar, o relacionar se modifica. A mesma transição ocorre com a percepção dos intérpretes. O texto/aluno assume um sentido para cada leitor/professor em cada momento que estabelece contato. A canção só pode existir, ser apreciada e compreendida se alguém a interpretar. Cada artista interpreta a mesma música, a mesma melodia, com o seu estilo, influenciado pelo momento histórico em que está inserido. Assim, não existe uma música $e m$ si, uma versão definitiva. Também não existe uma interpretação que soe como a definitiva, imutável daquela melodia. Educação, pesquisa e arte partilham a condição de, em sua atualização, sempre guardarem um lugar para o novo.

Recebido em 24 de março de 2014 Aprovado em 10 de maio de 2014

\section{Notas}

1 Compreendemos a temática da inclusão e exclusão em relação aos direitos à educação, à igualdade e à diferença.

20 presente trabalho amplia pesquisa do tipo estado da arte sobre o tema escolarização de alunos com TGD (Vasques, 2008; 2009). Nesse contexto, o recorte temporal 2000-2012 justifica-se pela estabilidade das bases de dados nacionais e possibilidade de acesso integral aos documentos pesquisados.

3 No presente artigo, há uma impossibilidade de referendar todos os documentos que compõem nosso acervo ou, ainda, as fontes documentais de nossa pesquisa. A intenção é divulgar o banco de dados o mais brevemente possível.

4 Em estudo anterior, sobre a produção discente brasileira no período entre 1987 e 2006, percebemos que as pesquisas tinham por foco principal o âmbito diagnóstico-clínico (Vasques, 2008; 2009).

5 As seis categorias apresentam o tema principal discutido pelos autores e foram contabilizadas uma única vez. As obras foram listadas em mais de um subtema.

6 O Método TEACCH é compreendido por alguns autores como uma das principais abordagens educacionais e clínicas. Parte da premissa de que os autistas aprendem melhor por visualização, apreciam rotinas e não são favoráveis a surpresas. Por isso, valoriza o aprendizado estruturado, dá importância à rotina e à informação visual. Segundo essa proposta, é necessário organizar e simplificar o ambiente, apresentando poucos estímulos sensoriais concomitantes. Isso facilita focar a atenção nos detalhes relevantes. A criança é avaliada individualmente. O objetivo básico é aumentar o funcionamento independente. O Currículo Natural Funcional (CNF) e o Programa de Ensino Individualizado (PEI) caracterizam-se por selecionar procedimentos de ensino compatíveis com as capacidades de alunos severamente prejudicados, objetivando torná-los independentes e produtivos. De maneira geral, tais propostas baseiam-se na funcionalidade das habilidades a serem adquiridas e na manutenção destas através de contingências naturais de aprendizagem (Assumpção JR., 2003). Na totalidade das pesquisas analisadas, estas concepções teóricas e práticas de atendimento educacional são amplamente reconhecidas pelas diferentes áreas do conhecimento, constituindo a principal recomendação no plano terapêutico e educacional. 


\section{Referências}

ADORNO, Theodor W. O Ensaio como Forma. In: Notas de Literatura I. São Paulo: Editora 31, 2003. P. 15-45.

ARROYO, Miguel. Políticas Educacionais e Desigualdades: à procura de novos significados. Educação \& Sociedade, Campinas, v. 31, n. 113, p. 1381-1416, out./ dez. 2010.

ASSOCIAÇÃO DE PSIQIATRIA AMERICANA. Manual Diagnóstico e Estatístico de Transtornos Mentais (DSM-IV-TR). Porto Alegre: Artes Médicas, 2002.

ASSUMPÇÃO JR., Francisco. Transtornos Abrangentes do Desenvolvimento. In: ASSUMPÇÃO JR., Francisco; KUCZYNSKI, Evelyn (Org.). Tratado de Psiquiatria da Infância e Adolescência. São Paulo: Atheneu, 2003. P. 265-280.

BAPTISTA, Claudio Roberto; CAIADO, Katia; JESUS, Denise. Educação Especial: diálogo e pluralidade. Porto Alegre: Mediação, 2008.

BAPTISTA, Claudio Roberto. Ação Pedagógica e Educação Especial: a sala de recursos como prioridade na oferta de serviços especializados. Revista Brasileira de Educação Especial, Marília, v. 17, p. 59-76, maio/ago. 2011.

BRASIL. Ministério da Educação. Secretaria de Educação Especial. Política Nacional de Educação Especial na Perspectiva da Educação Inclusiva. Brasília: MEC/SEESP, 2008.

BERQUEZ, George. O Autismo Infantil e Kanner. Estudo Histórico e Consequências Teóricas. In: MAZET, Phillip; LEBOVICI, Serge. Autismo e Psicoses da Criança. Porto Alegre: Artes Médicos, 1991. P. 20-30.

CHAUÍ, Marilena. Convite à Filosofia. 13 ed. São Paulo: Ática, 2005.

FERREIRA, Norma Sandra. As Pesquisas Denominadas "Estado da Arte". Educação e Sociedade, Campinas, v. 23, n. 79, p. 257-272, ago. 2002. Disponível em: $<$ http://www.propp.ufms.br/ppgedu/geppe/textoestadodaarte.pdf>. Acesso em: 15 jan. 2006.

GADAMER, Hans-Georg. Verdade e Método I. Petrópolis: Vozes, 2007 (Original de 1960).

GRIBOSKI, Claudia. Opinião. Inclusão: revista de educação especial, Brasília, v. 4, n. 1, p. 57, jan./jun. 2008.

HERMANN, Nadja. Pluralidade e Ética em Educação. Rio de Janeiro: DP\&A, 2002.

MANGUEL, Alberto. A História da Leitura. São Paulo: Companhia das Letras, 1997.

MARQUEZAN, Reinoldo. O Deficiente no Discurso da Legislação. Campinas: Papirus, 2009.

ORGANIZAÇÃO MUNDIAL DE SAÚDE. Classificação de Transtornos Mentais e de Comportamento da CID-10 - Descrições Clínicas e Diretrizes Diagnósticas. Porto Alegre: Artes Médicas, 1993.

PEREC, Georges. A Coleção Particular. São Paulo: Cosac \& Naify, 2006.

RICKES, Simone. Psicanálise e Educação: do vazio da determinação como propulsora da produção de sentidos. In: REUNIÃO ANUAL DA ASSOCIAÇ̃̃O DE PÓS-GRADUAÇÃO E PESQUISA EM EDUCAÇÃO, 2004, Caxambu. Anais... Caxambu: ANPED, out. 2004. P. 1-15. Disponível em: <http://www.anped.org.br/ reunioes/27/gt20/t2011.pdf>. Acesso em: 13 maio 2012. 
SÁNCHEZ GAMBOA, Silvio. Epistemologia da Pesquisa em Educação. Campinas: Práxis, 1996.

SANDER, Benno. A Pesquisa sobre Política e Gestão da Educação no Brasil: uma leitura introdutória sobre sua construção. Revista Brasileira de Política e Administração da Educação, Porto Alegre, v. 23, n. 3, p. 421-448, set./dez. 2007.

TURATO, Egberto. Tratado da Metodologia da Pesquisa Clínico-Qualitativa: construção teórico-epistemológica, discussão comparada e aplicação nas áreas da saúde e humanas. Rio de Janeiro: Vozes, 2005.

VASQUES, Carla K. Alice na Biblioteca Mágica: uma leitura sobre o diagnóstico e a escolarização de crianças com autismo e psicose infantil. 2008. 195 f. Tese (Doutorado em Educação) - Programa de Pós-Graduação em Educação, Universidade Federal do Rio Grande do Sul, Porto Alegre, 2008.

VASQUES, Carla K. Transtornos Globais do Desenvolvimento e Educação: análise da produção científico-acadêmica. In: REUNIÃO ANUAL DA ASSOCIAÇÃO DE PÓS-GRADUAÇ̃̃O E PESQUISA EM EDUCAÇÃO, 2009, Caxambu. Anais... Caxambu: ANPED, out. 2009. P. 1-15. Disponível em: <http://www.anped.org. br/reunioes/31ra/1trabalho/GT15-4469--Int.pdf>. Acesso em: 06 ago. 2013.

Carla K. Vasques é psicóloga, com formação em psicanálise. Doutora em Educação/UFRGS. Professora da Faculdade de Educação e do Programa de Pós-Graduação em Educação da UFRGS. Coordenadora do Núcleo de Pesquisa em Psicanálise, Educação e Cultura, NUPPEC/UFRGS. Desenvolve pesquisas sobre sujeitos da educação especial e processos de escolarização. E-mail: k.recuero@gmail.com

Claudio Roberto Baptista é doutor em Educação pela Università di Bologna. Professor da Faculdade de Educação e do Programa de Pós-Graduação em Educação da UFRGS. Coordena o NEPIE-Núcleo de Estudos em Políticas de Inclusão Escolar da UFRGS. Desenvolve pesquisas sobre os processos de inclusão escolar e sobre a educação especial. E-mail: baptistacaronti@yahoo.com.br 